\title{
Mapping of Substrate Categories Changes in Exposure to Coral Reefs Using Alos Avnir-2 and Spot 7 Images in the South Area of Kotabaru District
}

\author{
Budimansyah*, Baharuddin, Hamdani \\ Faculty of Fisheries and Marine Science, Lambung Mangkurat University, Banjarbaru, Indonesia, 70714 \\ * Correspondence: budi.mcp@gmail.com
}

Received: 11 November 2019; Accepted: 23 November 2019; Published: 25 November 2019

\begin{abstract}
The South of Pulau Laut is an area which is included in the Coral Triangle and Aquatic Conservation Areas. The purpose of this study was to map changes in the extent of coral reefs based on the class of substrate categories and objects on exposure to coral reefs in the southern waters of Sea Island within 6 years from 2011- 2017 using SPOT 7 satellite imagery in 2017 and AVNIR ALOS-2 in 2011. Using the method of Lyzenga Dept Index for basic invariant detection of waters. Based on the results of substrate-based classification using both satellite images overlay, there has been a decline for the coral category as much as -19.21 ha, seagrass and algae as much as -3.57 ha. On the Contrary, the category of open substrate has Increased by 22.77 ha. Object-based classification results using the Object Based Image Analysis (OBIA) method have a reduction in area for the hard coral category (HC) of -1.66 ha, hard sand mixed with sand (HC S) of -15.99 ha, dead coral overgrown with algae and sand (DCA S) of 0.39 ha, algae and seagrass (FS) covering an area of -1.65 ha, sand-mixed coral fragments (RS) of 4:45 ha. On the other hand, there was an increase of in the area.
\end{abstract}

Keywords: AVNIR ALOS-2, changes, coral reef, mapping, remote sensing, SPOT.

\section{Introduction}

Coral growth is very dynamic over time as affected by environmental conditions and human activities. According to Burke et al., (2012) split the six factors that influence the growth of coral reefs that human activities local, overfishing and destructive, pollution originating from watersheds (DAS), coastal development, pollution of the sea and an increase in the temperature of sea water. Furthermore, more than $85 \%$ of reefs in the Coral Triangle region including Indonesia waters under threat.

Based on research LIPI 2016 coral reefs in Indonesia has decreased each year (Giyanto et al., 2017). The results of the verification and analysis of data on 108 locations with 1,064 stations, obtained by percentage of live coral cover very good status with cover $76 \%-100 \%$ of about $6.39 \%$, are in good standing with cover $51-75 \%$, amounting to $23.40 \%$. The rest, namely the status of enough to cover 26 $50 \%$ approximately $35.06 \%$ and the status broken with cover $0-25 \%$ of about $35.15 \%$.

One of the areas in Indonesia which was included in the Coral Triangle Region, namely the southern part of Sea Island and also includes a conservation area. Administratively, the region including the District of Sea Island Tanjung Selayar District, South Kalimantan Kotabaru (CBS, 2017). The result of the identification in 2015 of coral reefs in the waters surrounding the island Turmeric and have wide exposure of 556.83 hectares of coral reef, which is divided into categories of coral covering 140.71 ha (9.44\%), while the mixture of coral category covering 69.44 ha $(12.47 \%)$ and the remaining categories 
of other substrate types namely sand, sargassum, sargassum mixed sand and rock the size of 346.68 ha (62.26\%). For the category of live rock / corals (hard coral) on the island of Turmeric and small islands around it was found at a depth range of 1-8 m. The results of image analysis and field observations indicate that most of the coral damaged by sedimentation caused by run-off when the rainy season so the impact on freshwater runoff, turbidity and an increase in nutrients in the water (DKP, 2015). From the analysis, just look at the causes of the damage but did not see changes in its range.

Changes in the area of coral reef ecosystems in the waters south of Pulau Laut region could be affected natural factors such as climate changes such as el-nino which causes an increase in sea surface temperature and la-nina which led to an increase in precipitation, causing run-off. These factors also led to increased nutrients and sedimentation resulting in damage to the coral reefs. Factors human activities also contribute to the degradation of coral reefs such as land clearing, port activities, domestic waste and coral mining for building materials. The accumulation of these two factors may result in damage to the coral reef ecosystem which is indicated by changes in substrate category and reduced the extent of live coral cover.

Changes in the area of coral reefs can be estimated using SPOT satellite imagery AVNIR 7 and ALOS2 which is medium resolution satellite imagery. Satellite imagery analyzed by lyzenga method to detect objects on the seabed. Then do Classification image analysis results lyzenga to divide a class of objects in the bottom waters. The image of the results of classification accuracy test was done to see the level of accuracy of the results of image analysis. Test accuracy is done by looking at the level of classification correctness of the data field test sample (Ground Truth). Ground Truth marks obtained by observation location using the Global Positioning System (GPS), and lists the percentage of coral cover. Satellite imagery data accuracy test results are used to create a map of the distribution of coral reefs.

\section{Territorial Boundaries}

This study is located in the southern part of Pulau Laut Kotabaru district, which includes the Teluk Tamiang, Terusan Tengah Island, Pulau Kunyit, Tanjung Sungkai, Tanjung Tengah dan Tanjung Ujung.

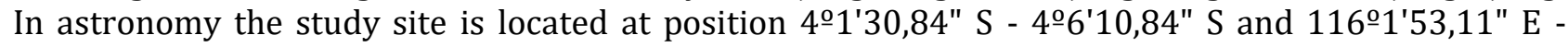
$116^{\circ} 6^{\prime} 39,41^{\prime \prime}$ E with a comprehensive $\pm 7.753,59$ ha.

\section{Theoretical Limits}

Limits the scope of the material from the study include:

1. Analysis of satellite imagery AVNIR ALOS-2 in 2011 and SPOT 7 satellite imagery in 2017 to assess changes in coral reefs.

2. Data Ground Control Point (GCP) to see the level of accuracy of the image analysis.

\section{Formulation of The Problem}

1. How to map changes in the area of coral reefs by category class objects coral reef substrate and southern waters of Sea Island within 6 years from 2011 to 2017 ?

2. How to provide data and information for policy makers about changes in the area of coral reef ecosystems from $2011-2017$ ?

\section{Research Methods}

\section{Time and Location}

This research was conducted in November 2017 - November 2018, located in the southern region of the island (Figure 1). The process of data analysis conducted at the Laboratory of Geographic Information Systems and Remote Sensing Marine, Marine Science Study Program Lambung Mangkurat University Banjarbaru.

Tools and Materials

Table 1. Tools and Materials Used in this Research.

\begin{tabular}{|l|l|l|l|}
\hline No. & Tools and Materials & Amount & Information \\
\hline & Tool & & \\
\hline 1 & GPS (Global Positioning System) & 1 (unit) & Marking positions and GCP \\
\hline 2 & Stationary & 1 (set) & Recorded data \\
\hline 3 & Under Water Camera & 1 (unit) & Documenting Activity \\
\hline
\end{tabular}




\begin{tabular}{|l|l|l|l|}
4 & Snorkeling Equipment & 1 set) & Underwater observation tools \\
\hline 5 & Ship & 1 (unit) & Facilitate data retrieval \\
\hline 6 & Computer hardware & 1 (unit) & Data analysis \\
\hline & Material & 1 & Research site description \\
\hline 1 & Map of planned activities & $\begin{array}{l}\text { Basic data mapping coral reefs in } \\
2017\end{array}$ \\
\hline 2 & SPOT image recording 7 year 2017 & 1 & $\begin{array}{l}\text { Basic data mapping coral reefs in } \\
2011\end{array}$ \\
\hline 3 & $\begin{array}{l}\text { ALOS-AVNIR 2 years of recording } \\
\text { 2011 }\end{array}$ & 1 & \\
\hline
\end{tabular}

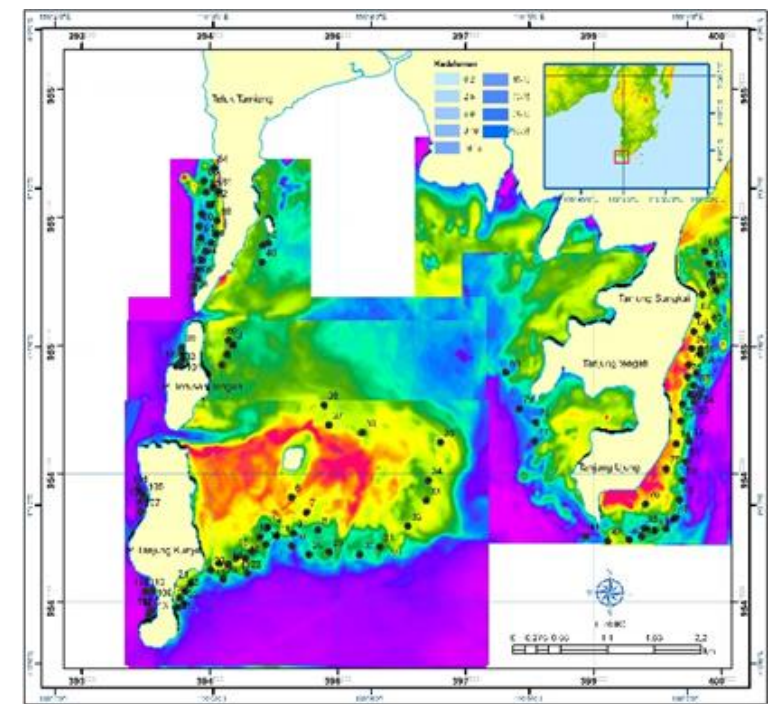

Figure 1. Site Map Research

Initial processing of Satellite Imagery

Initial processing stage satellite image (image preprocessing) is performed to correct the original image data (raw data) into a satellite image ready for interpretation. Work being undertaken includes error correction due to scattering particles in the atmosphere are captured by satellite imagery (radiometric correction), fixes the position error recording satellite imagery to the reference earth (geometric correction), masking and cropping, the composite image and sharpening the object in the image by stretching spectral value image (LIPI, 2014).

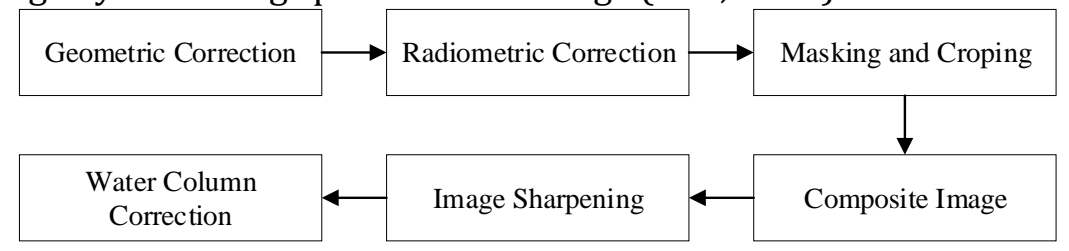

Figure 2. Flowchart of initial processing of satellite imagery

Water column correction formula:

$$
Y=(\ln \text { band } 1)+\left(\frac{k i}{k j} \times \ln \text { band } 2\right)
$$

$\frac{k i}{k j}=a+\sqrt{a^{2}+1}$

$a=\frac{(\text { varian band } 1-\text { varian band } 2)}{(2 \times \text { covarian band } 1 \text { dan band } 2)}$

$\mathrm{Ki} / \mathrm{kj}=$ ratio coefficient blue channel and the green channel.

\section{Field Test Sampling (Ground Truth)}

Determination of field test sample refers to the habitat mapping LIPI shallow marine waters by 2014. The samples were done using purposive and proportional random sampling. Purposive sampling taking into account the diversity of habitat class basis shallow marine waters. Proportional random sampling is used in determining the sample point at the location, and the number of points determined representative sample and proportionately based on the size of the area mapped. Workplace or tentative map which has been printed, is used as a guide in the field. 


\section{Substrate Based Image Classification}

In this research, the substrate-based image classification method is not supervised classification (unsupervised). Supervised classification was done by classifying pixel image into several classes based only on certain statistical calculations without specifying the sample pixels (training) which is used as a reference for classification. Classification for image-based substrate with no guided method is divided into three classes are presented in Table 3 (LIPI, 2014).

Table 3. Class basic habitat shallow marine waters

\begin{tabular}{|c|c|c|}
\hline No. & Class & Information \\
\hline 1 & Habitat Coral & $\begin{array}{l}\text { This habitat is composed by rock material composed of } \\
\text { live coral and dead coral, has wide enough that the } \\
\text { spreading and can be distinguished on the other habitat } \\
\text { types. The habitat is generally found in the end of the reef } \\
\text { flat area overlooking the sea, from the reef crest, edge } \\
\text { (reef edge) to the slopes of the reef (reef slope), In some } \\
\text { areas of coral reef habitats are found spreading of starting } \\
\text { from the coastline up to the edge. }\end{array}$ \\
\hline 2 & Seagrass Habitat \& Algae & $\begin{array}{l}\text { Habitat is arranged on a bed of seagrass which is quite } \\
\text { extensive, and is usually found in the basin on the reef } \\
\text { (reef flat). In appearance for true color composite image } \\
\text { has a dark hue and smooth texture. }\end{array}$ \\
\hline 3 & Habitat Substrate Open & $\begin{array}{l}\text { Habitat are largely dominated by the substrate of sand, } \\
\text { rubble, stone, or a mixture of these substrates. Rona in } \\
\text { true color composite image tends to be bright. }\end{array}$ \\
\hline
\end{tabular}

Source: LIPI, 2014

\section{Object Based Image Classification}

In this research-based classification of objects or Object-Based Image Analysis (OBIA). This classification recognizes the object based on the group of pixels to classify the pixel value on proximity to the pixels in a particular class based on a sample of pixels.

Classification for image-based object with methods OBIA divided into several classes, namely live coral (HC), dead coral (DC), dead coral covered with algae (DCA), rubble (R), sand (S), benthic algae and seagrasses (FS). The classification is identified to provide the identity of the class of image classification results. The process of re-interpretation can be assisted visually using color composite image based on the knowledge interpreter, or based on the performance data as a basis classification field.

\section{Methods of Observation and Measurement Objects Elementary Bodies}

Measurement of basic water objects include visual identification for estimating the cover of various object types of bottom waters. Data taken also taken the form of point coordinates using GPS and a data base substrate taken using manta tow technique snorkeling around the point of the station with the bottom waters and taking photos on a field test sample.

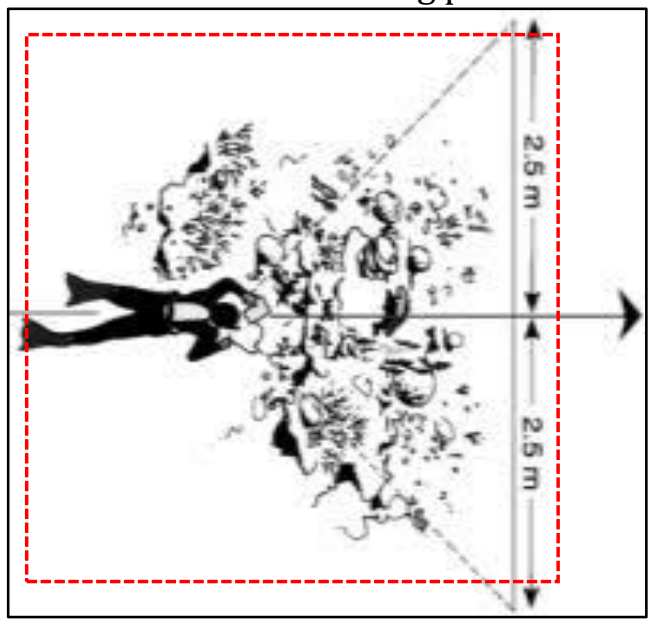


Figure 3. How to observing and measuring objects on the field

Data analysis

Test Accuracy

This test is performed to determine the value of the quality of the analysis of the resulting data. Limit of acceptable accuracy for basic habitat map shallow water based on ISO 7716: 2011 on the basis of Habitat Mapping shallow marine waters which decreased by $60 \%$. Test the accuracy of the classification results using the following equation:

Information:

$$
K I=\frac{J K I}{J K L} \times 100 \%
$$

$\mathrm{KI}=$ Accuracy of Interpretation

$\mathrm{JKI}=$ Total Truth Interpretation

JSL = Total Sample Courses

Accuracy test carried out on SPOT imagery in 2017, if the test results accuracy is above $60 \%$, then the results of data analysis can be accepted. then used as a reference for image analysis AVNIR ALOS-2 in 2011. Then calculate the area of the base substrate upon exposure to coral reefs.

\section{Exposure Calculation Substrate Size Changes Coral Reef}

Coral reefs are calculated is the result of data analysis AVNIR ALOS-2 in 2011 and SPOT 72017 that have been classified by the image classification method based substrates. The classification results in the form of polygon data in shapefile format (shp) are then calculated its range. The extent of data overlay to calculate changes in the area on a coral reef at the site of exposure research. Overlay referred to as a visual operation that requires more than one layer to be combined. Schematic map overlay analysis is presented in figure 4.

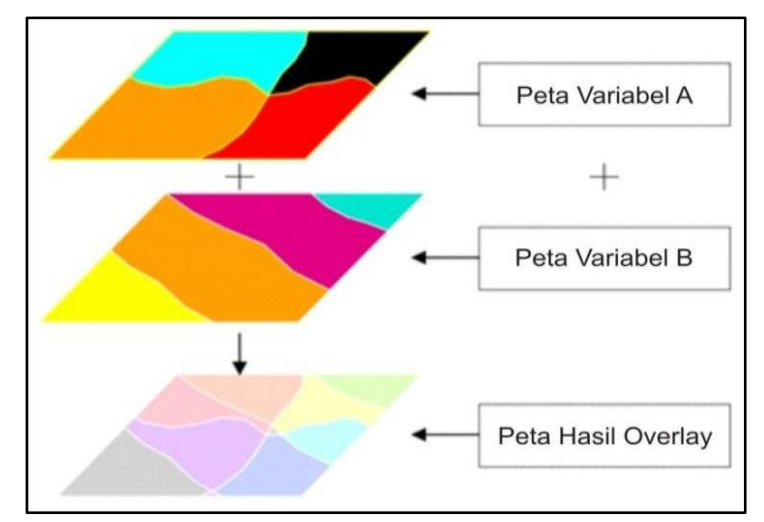

Figure 4. Schematic maps with GIS overlay analysis (Pramudiya 2008)

\section{Results and Discussion}

\section{Accuracy Test Image}

\section{Substrate-Based Classification}

Results-based classification substrate using supervised classification techniques (Unsupervised classification) obtained three categories: coral reefs, sand and open substrate. The three categories are determined based on the technical guidelines basic habitat mapping shallow marine waters by 2014 . LIPI classification Results tested accuracy with field data. Can be seen in Table 4.1 classification accuracy of test results is not supervised.

Table 4. Test the accuracy of object-based classification

\begin{tabular}{|l|l|l|l|l|}
\hline No. & Category & Amount of Data & Anomaly & Accuracy (\%) \\
\hline 1 & Coral reefs & 79 & 8 & 89.87 \\
\hline 2 & Algae and Seagrass & 24 & 16 & 33.33 \\
\hline 3 & substrate Open & 10 & 3 & 70 \\
\hline Amount & $\mathbf{1 1 3}$ & $\mathbf{2 7}$ & $\mathbf{7 6 . 1 1}$ \\
\hline
\end{tabular}

Source: Results of Analysis 2018 
From Table 4 it can be seen the level of accuracy of test results base classification object of value between $33.33 \%-89.87 \%$ with an average of $76.11 \%$. Test the accuracy of test data obtained from the 113 field samples were divided into three categories namely coral reefs as much as 79 data, as many as 24 open substrates of data, algae and seagrass 10 data.

\section{Object Based Image Classification}

Class grouping these categories is the result of the classification is based on the object or Object Based Image Analysis (OBIA) to recognize objects based on groups of pixels. Group classes are the result pixels lyzenga analysis were confirmed by the data GCP. GCP data acquisition in the form of point coordinates and class reef substrate category totaling 113 points. Classes are divided into nine categories, namely class Hard coral (HC) and dead coral covered with algae (HC DCA), hard corals and sand (HC S), hard corals and dead coral mixed with sand (HC DC S), seagrass and algae (FS), coral reefs die overgrown with algae mixed sand (DCA S), seagrass and algae mixed with sand (FS S), Denomination rock mixed with sand (RS), sand (S). In table 4 can be seen the result of coral reef cover classes grouping and accuracy of the test results of the analysis of the data lyzenga with GCP.

Table 5. Test the accuracy of object-based classification

\begin{tabular}{|l|l|l|l|l|l|}
\hline No. & Class & pixel Value & Amount of Data & Anomaly & Accuracy (\%) \\
\hline 1 & HC DCA & 62.81 to 69.12 & 6 & 1 & 83.33 \\
\hline 2 & HC & 75.89 to 81.66 & 17 & 1 & 94.12 \\
\hline 3 & HC S & 81.93 to 119.92 & 41 & 4 & 90.24 \\
\hline 4 & HC DC S & 118.76 to 122.21 & 15 & 1 & 93.33 \\
\hline 5 & FS & 122.77 to 123.46 & 3 & 0 & 100 \\
\hline 6 & DCA S & 123.45 to 129.75 & 5 & 1 & 80 \\
\hline 7 & FS S & 134.55 to 168.64 & 7 & 0 & 100 \\
\hline 8 & RS & 154.22 to 156.30 & 7 & 1 & 86 \\
\hline 9 & S & 159.44 to 196.75 & 12 & 0 & 100 \\
\hline \multicolumn{2}{|l|}{} & $\mathbf{1 1 3}$ & $\mathbf{9}$ & $\mathbf{9 2 . 0 4}$ \\
\hline
\end{tabular}

Source: Results of Analysis 2018

Based on Table 5 shows the reef substrate category class groupings based on the value of pixels (pixel value) is divided into 9 classes. The category class tested the level of accuracy with GCP of data captured in the field. This level of accuracy in each grade category ranged between $80 \%-100 \%$ with an average of $93.81 \%$ of the 113 data by $6.19 \%$ experiencing anomalies (errors of commission). According to Green et al., (2000) classification results and the accuracy test can be used as a reference in determining the object to the exposure of coral reefs. In this study the dynamics of change in reef exposure within 6 years from 2011 to 2017 can be detected with excellent accuracy.

Exposure Substrate Size Calculation Changes Coral Reef

\section{Distribution Based Substrate-Based Category Class of 2011}

The result of class classification base categories substrate carried on AVNIR ALOS-2 in 2011. From the results of the classification obtained three grade categories, coral, substrate open, algae and seagrass. The graph in Figure 6 can be seen in the open class category substrate has an area of 739.417 ha, 557.092 ha category class coral and seagrass and algae category covering 46.521 ha.

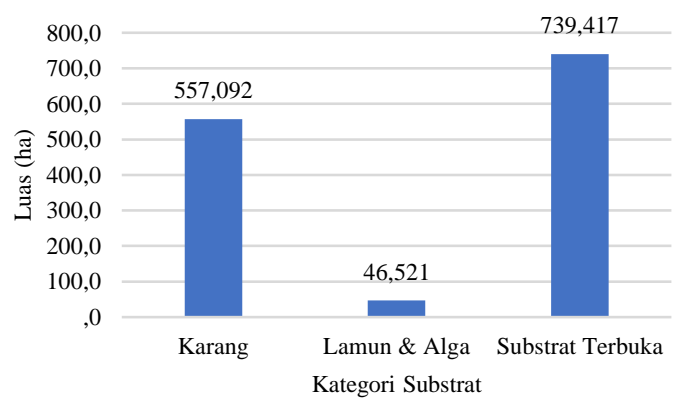

Figure 5. Substrate-Based Graph Category Class of 2011

2. Distribution Based Substrate-Based Category Class Year 2017 
The result of class classification base categories substrate carried on SPOT image 7 2017. From the results of the classification obtained three grade categories, coral, substrate open, algae and seagrass. The graph in Figure 7 can be seen in the open class category substrate has an area of 762.190 ha, 537.885 ha category class coral and seagrass and algae category covering 42.955 ha.

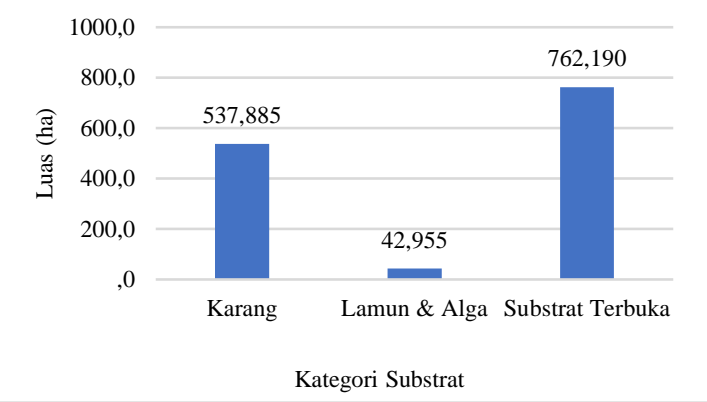

Figure 6. Graph-Based Substrate Class category Year 2017

3. Changes Substrate Size of Class category Year 2011 - 2017

Based on the results of the class overlay substrate category in 2011 and 2017 is presented in Figure 11 there is a change of class categories. Graph difference substrate category class area in $2011-2017$ is presented in Figure 8 can be seen corals category experienced a reduction of as much as -19.207 ha area, seagrass and algae-experienced reductions of $3.566 \mathrm{ha}$, is inversely proportional to the category of open substrate which has the addition of as much as 22.773 ha area.

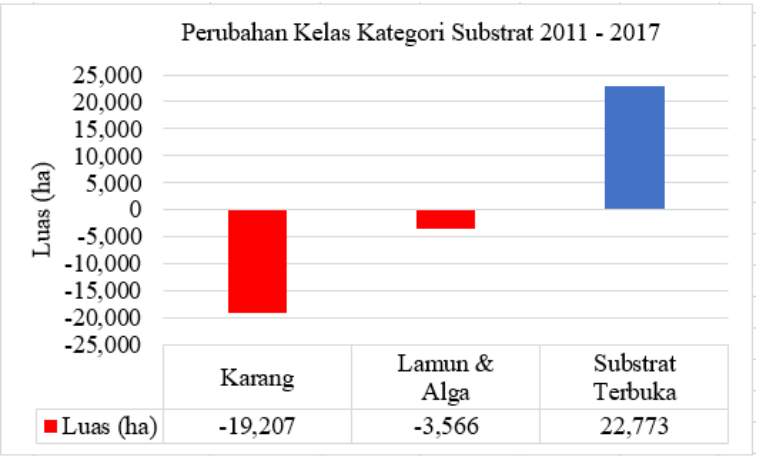

Figure 7. Difference Graph Class Category Area of Substrate 2011 - 2017

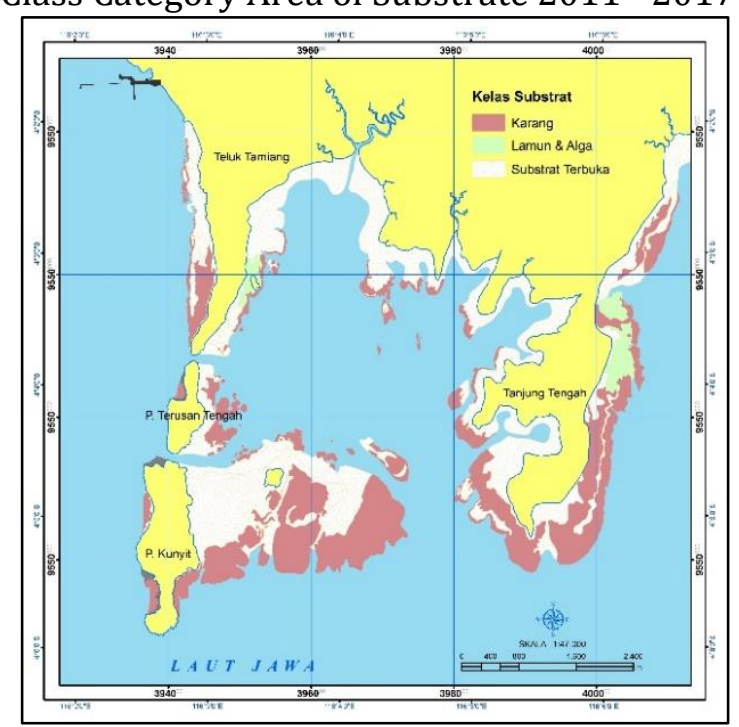

Figure 8. Map Class Category Substrates in 2011 


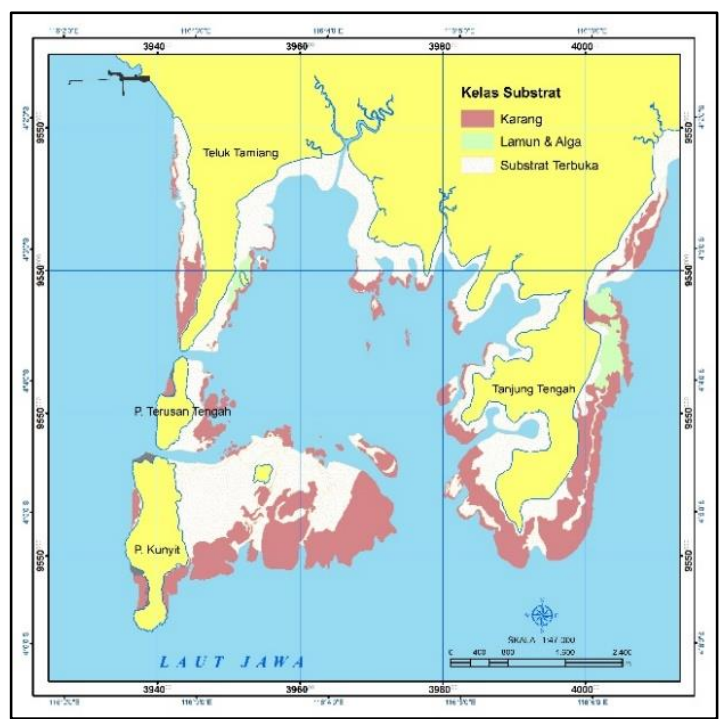

Figure 9. Map grade category substrate 2017

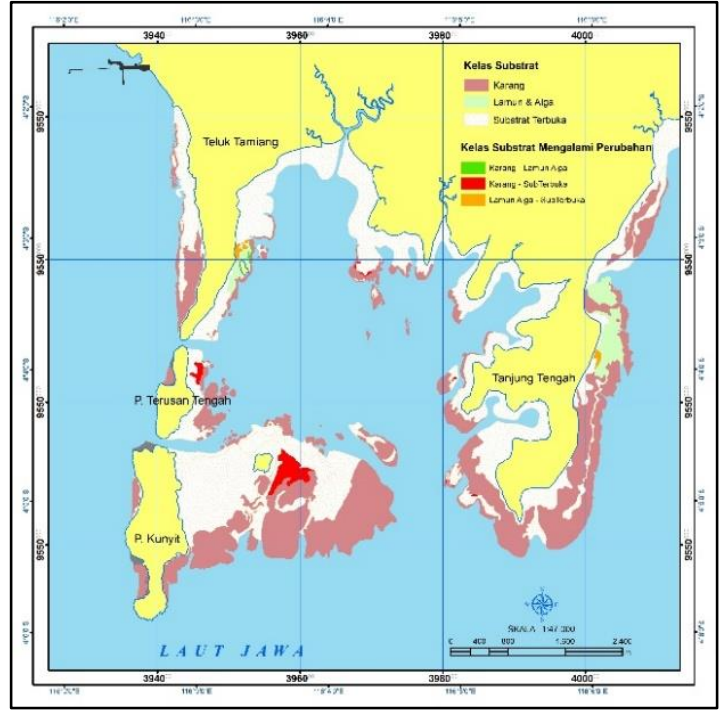

Figure 10. Map Changes Substrate Class category Year 2011 - 2017

\section{Exposure Calculation Object Size Changes Coral Reef}

\section{Distribution Based on Object-Based Category Class of 2011}

The results of the classification AVNIR ALOS-2 in 2011 and SPOT 7 in 2017, it looks pretty clear the display differences in the pattern of this type of bottom waters. Based on the pattern of the basic types are divided into nine classes reefs categories, namely hard corals (HC) with an area of 170.80 hectares or $12.72 \%$ of the total area of the reef, hard coral and dead coral covered with algae (HC DCA) has an area of 1,65 ha or $0.12 \%$, hard coral cover has mixed with sand and dead coral (HC DC S) 121.21 ha or $9.03 \%$ of the total area of forest cover, hard rock mixed with sand (HC S) has an area of 237.13 ha or $17.66 \%$ of the total area of forest cover. The next category of seagrass and algae (FS) has an area of 13.95 ha, or $1.04 \%$, seagrass algae mixed with sand (FS S) 187.94 hectares or $13.99 \%$, dying coral reefs overgrown with algae mixed with sand (DCA S) with 27 spacious, 15 ha or $2.02 \%$. Besides the category rubble mixed with sand (RS) 105.79 ha or $7.88 \%$, Sand (S) 477.42 hectares or $35.55 \%$ of the total area of the reef. Coral reefs are scattered in the survey locations represent areas reef flat and reef crest. 


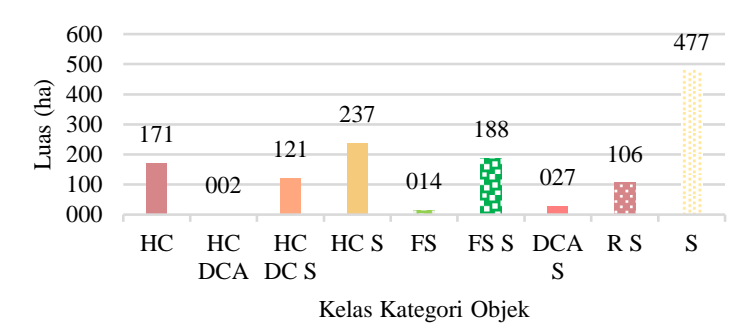

Figure 11. Graph-Based Object Size Category Class of 2011

\section{Distribution Based on Object-Based Class category Year 2017}

Based on the analysis of the object of exposure to the reef using 2017 SPOT image 7 generated 9th grade category substrate. They show that was found to grade category Hard coral (HC) with an area of 169.13 ha $(12.65 \%)$, class of hard coral and dead coral covered with algae (HC DCA) has an area of 1.65 ha $(0.12 \%)$, spacious hard coral cover and coral die mixed with sand (HC DC S) with an area of 121.21 ha $(9.07 \%)$, hard rock mixed with sand (HC S) has an area of 221.14 ha $(16.47 \%)$. The next category of seagrass and algae (FS) has an area of 12.29 ha $(0.92 \%)$, seagrass algae mixed with sand (FS S) with an area of 193.63 ha (14.48\%), dead coral reefs overgrown with algae mixed with sand (DCA S) with an area of 26.76 ha (2.00\%). Besides the category rubble mixed with sand (RS) around 101.34 ha $(7.58 \%)$, the category of sand (S) with an area of 495.88 ha (36.92\%). Coralreefs are scattered in the survey locations represent areas reef flat and reef crest.

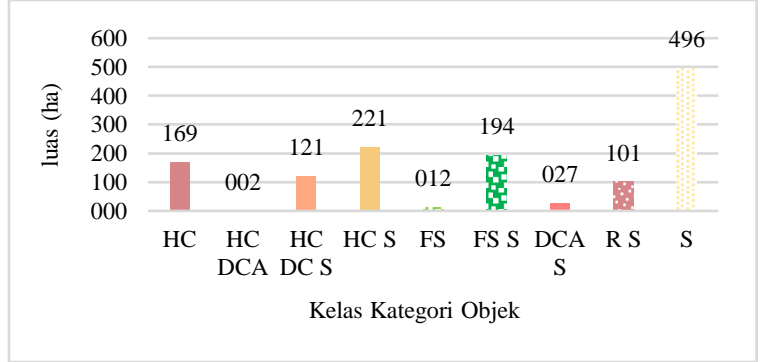

Figure 12. Graph-Based Object Category Class Size Year 2017

\section{Changes in Size of Class Category Object of the Year 2011 to 2017}

Changes in question is the extent of changes in each category of exposure reef substrate in different time periods. The amendment shows the extent of the bias or changes in other categories of the substrate to form the substrate category. Based on the results of image processing in 2011 and 2017 were corrected image with field data, there are differences in the extent of the reef substrate category that has been analyzed and grouped by categories of objects can be seen in Figure 14.

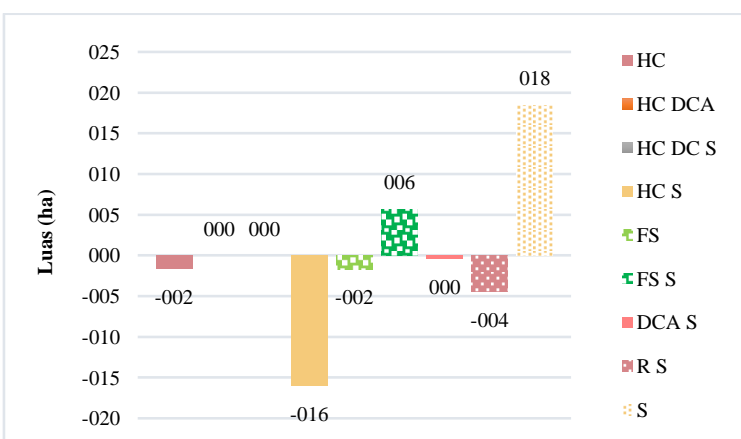

Figure 13. The extent offset graph Based Object Class Category Year 2011-2017

Changes in question is the extent of changes in each category of exposure reef substrate in different time periods. The amendment shows the extent of the bias or changes in other categories of the subs14 found a reduction of the image area to the category of hard corals (HC) of -1.66 ha $(-0.97 \%)$. Same with HC, broad categories of hard coral cover substrate mixed with sand (HC S) also decreased by a margin of -15.99 cover ha $(-6.74 \%)$, Category overgrown with algae and dead coral sand (DCA S) reduced $-0,39$ ha $(-1.45 \%)$, the condition is also accompanied by algal cover and seagrass (FS) which decreased -1.65 cover ha $(-11.85 \%)$ and category Denomination of coral mixed with sand (RS) also suffered ha decreased by $-4.45(-4.21 \%)$. 
The dynamics of changes in the area of the substrate category DCA category S, FS, HC, HC S and RS allegedly by anthropogenic and natural factors. Anthropogenic factors that contribute to changes in the area of substrate exposure category reefs which are exposed keel and anchor. While natural factors that contribute to changes in the reef area is the sedimentation of the river mouth location studies carried particles of sediment from land to water, other natural factors are sedimentation derived from waves and ocean currents lift the sediment particles to the coral reef.

In contrast to the category of algae and seagrass mixed with sand (FS S) has the addition of the total area of 5.69 ha (3.03\%) and the category of sand (S) increased the area of 14.46 ha (3.03\%).

Change class category in the study area are caused by anthropogenic factors such as exhaust anchor and was hit by the hull as well as natural factors, namely sedimentation and increased nutrient.

Category group changes showed that habitat changes from one class category substrate to another substrate category class with area 31.84 ha in the area of research and is divided into 9 classes reef substrate category changes. Based on these results it can be stated that the analysis of changes in this study generates information base substrate category changing dynamics can be seen in Table 6 .

Table 6. Changes in Class Categories Objects Based on Years 2011 and 2017

\begin{tabular}{|c|l|l|c|c|c|c|}
\hline \multirow{2}{*}{ No. } & \multirow{2}{*}{$\mathbf{2 0 1 1}$} & $\mathbf{2 0 1 7}$ & $\begin{array}{c}\text { Extents } \\
\text { (ha) }\end{array}$ & \multicolumn{2}{|c|}{ Factor } & \multirow{2}{*}{ Information } \\
\hline 1 & DCA S & S & 0.39 & $\checkmark$ & & sedimentation \\
\hline 2 & FS & S & 1.65 & $\checkmark$ & & sedimentation \\
\hline 3 & FS S & S & 14.98 & $\checkmark$ & & sedimentation \\
\hline 4 & HC & RS & 0.13 & $\checkmark$ & $\checkmark$ & $\begin{array}{c}\text { Extreme waves, Exiles } \\
\text { anchor and getting hit by } \\
\text { keel }\end{array}$ \\
\hline 5 & HC & HC S & 1.53 & $\checkmark$ & & sedimentation \\
\hline 6 & HC S & S & 14.63 & $\checkmark$ & & sedimentation \\
\hline 7 & HC S & FS S & 1.93 & $\checkmark$ & $\checkmark$ & $\begin{array}{c}\text { Sedimentation and } \\
\text { increased nutrient }\end{array}$ \\
\hline 8 & HC S & RS & 1.42 & & $\checkmark$ & $\begin{array}{c}\text { Exiles anchor and getting } \\
\text { hit by keel }\end{array}$ \\
\hline 9 & RS & S & 4.45 & $\checkmark$ & & sedimentation \\
\hline
\end{tabular}

Source: The results of the analysis in 2018

The change category caused by sedimentation. Sedimentation is a process that transport material deposition by water media. Marine sedimentation derived from a variety of sources of material derived from erosion of material covering rock fragments of various sizes and shapes, dead organisms are then carried to the sea by a variety of processes. Marine sediments may also come from air, water and land. However, most of the material originated from terrestrial sedimentation carried by the river flow.

Pressure sedimentation can cause the death of coral reefs, as most corals cannot survive in the presence of heavy sediments, which cover and clog the administration structure of food. Sedimentation rate causes an increase in turbidity which can result in reduced brightness in the water against light penetration also resulted in a body of water. Sediment that contain nutrients and organic matter can result in the growth of algae on a large scale (Blooming algae).

Changes category of hard coral mixed with sand (HC S) be the class of algae and seagrass mixed with sand (FS S) with an area of 1.93 ha caused by sedimentation and increased nutrient. Sedimentation and increased nutrients coming from the mainland and brought into waters through run off. According Cahyadi (2013) organic and inorganic materials from mainland directly down to the waters through run-off and the impact on water quality. 


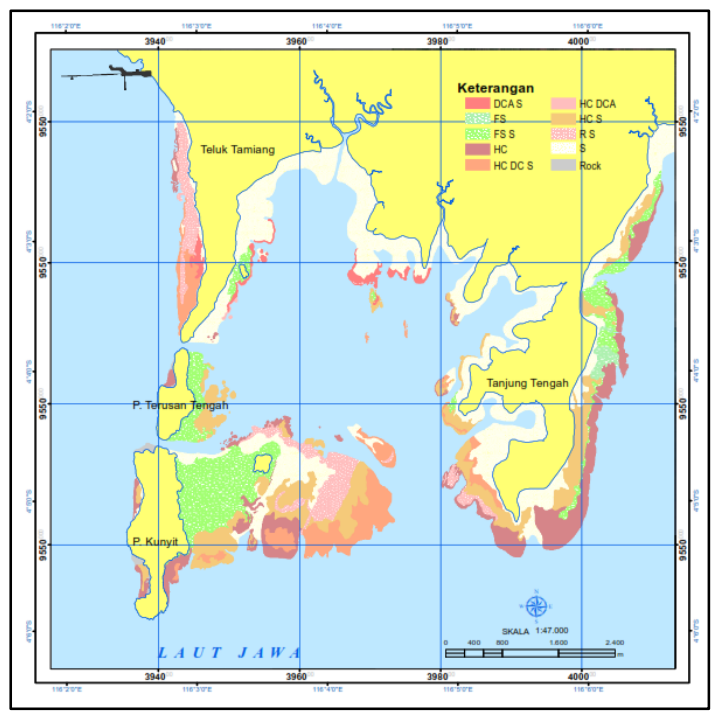

Figure 14. Map-Based Object Class Category 2011

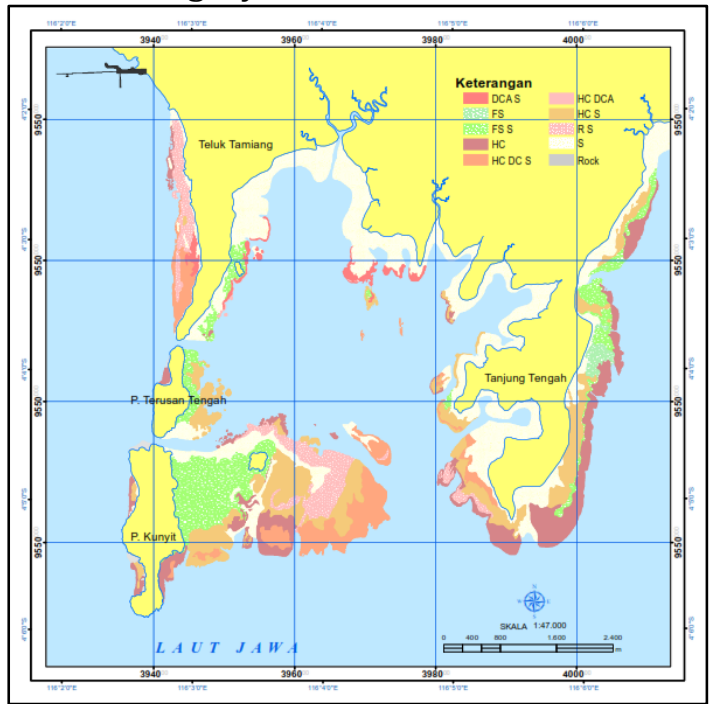

Figure 15. Map-Based Object Class Category 2017

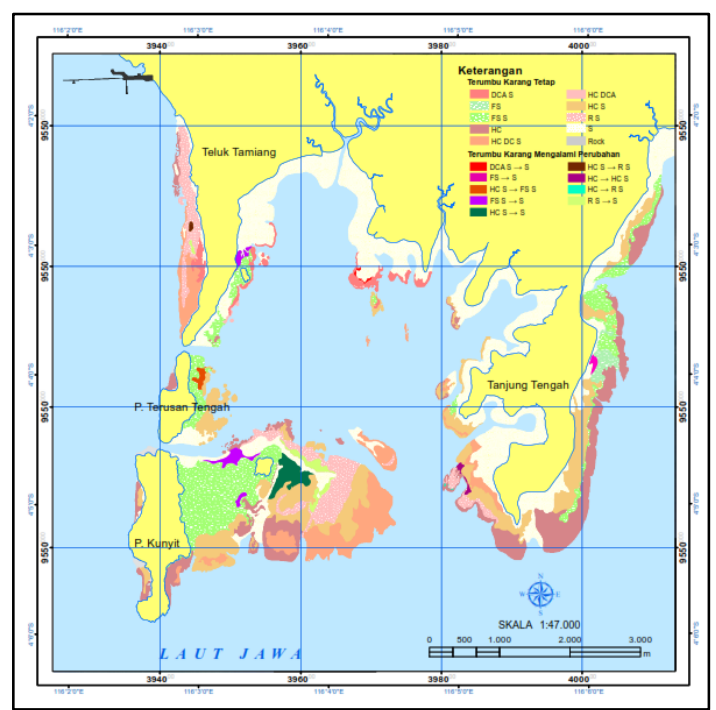

Figure 16. Category-Based Object Class Changes 2011 - 2017

\section{Conclusions}

Based on the results obtained broad-based classification substrate exposure coral reefs in the South Sea island of Kotabaru district of 1343.03 ha. The results of the second overlay image of the ALOS 
satellite image AVNIR-2 (2011) and SPOT 7 (2017) shows the changes in the area for corals category class of 557.09 ha to 537.89 ha or decreased -19.21 ha, seagrass and algae category from 46.52 ha to 42.96 ha decreased -3.57 , while the substrate category is open from 739.42 ha to 762.19 ha or an addition of 22.77 ha.

Object-based classification results are changes in the area found a reduction in the extent of the category of hard corals (HC) of -1.66 ha, hard rock mixed with sand (HC S) of -15.99 ha, dead coral overgrown with algae and sand (DCA S) as much as -0.39 ha, algae and seagrass (FS) covering -1.65 ha, broken rock mixed with sand (RS) of 4.45 ha. Conversely which has the addition of extents that is in the category of algae and seagrass mixed with sand (FS S) of 5.69 ha and sand category (S) covering an area of 14.46 ha.

\section{References}

Badan Pusat Statistik. 2017. Kecamatan Pulau Laut Tanjung Selayar Dalam Angka. Kotabaru.

Burke L, Reytar K, Spalding M dan Perry A. 2012. Reefs at Risk Revisited in the Coral Triangle. World Resource Institute.

Cahyadi, A. 2013. Analisis Dampak Intrusi Air Laut Terhadap Airtanah di Pulau Koral Pramuka Majalah Geografi Indonesia, Vol. 31, No. 2

Green, E.P., P.J. Mumby. A.J. Edwards, and C.D. Clark. 2000. Remote sensing handbook for tropical coastal management. UNESCO, Paris.

Giyanto, Abrar M, Hadi T.A, Budiyanto A, Hafizt M, Salatalohy A dan Iswari M.Y. 2017. Status Terumbu Karang Indonesia 2017. CoreMap-CTI.

LIPI. 2014. Panduan Teknis Pemetaan Habitat Dasar Perairan Laut Dangkal. Critc Coremap II LIPI. Jakarta. 